ENSAIOS

\section{DIÁLOGOS CONSISTENTES EM TEMPOS LÍQUIDOS}

DIALOGUES CONSISTING IN LIQUID TIMES

DIÁLOGOS CONSISTENTES EN TEMPOS LÍQUIDOS

\section{RESUMO}

Este ensaio pretende apresentar um texto provocativo e, ao mesmo tempo, ensejar uma reflexão comportamental sobre a situação hodierna dos relacionamentos humanos na gestão empresarial, tendo como fulcro, a espiritualidade cristã e o respeito à dignidade da pessoa humana, nas relações interpessoais, dentro do ambiente de trabalho. Tomamos como referência e fundamentação teórica, a citação bíblica do Evangelho de João capítulo 4 e versículos de 1 a 29. Ali, são abordadas as realidades da cultura líquida e os influxos dessa realidade, na problemática do ser humano como ente de relações. Ajudou-nos a aprofundar o tema o contributo teórico de Bauman (2009) e Ravasi (2014) dentro do paradigma do pensamento líquido e da hermenêutica teológica da fonte bíblica Joanina. O aludido trabalho apresenta de forma humilde e despretensiosa o diálogo de Jesus de Nazaré e uma mulher estrangeira à margem de um poço, onde se desvela o método mais humano de dialogar, acolher e corrigir de um líder amoroso, que vai além da realidade líquida oferecendo um sólido projeto vida interior, para aquela mulher e para a pessoa humana, que se compromete com o bem de seu empreendimento e daqueles que colaboram consigo, em um projeto administrativo e existencial bem sucedido.

Palavras-chave: Sociedade líquida. Paradigma do pensamento líquido. Hermenêutica teológica.

\begin{abstract}
This essay intends to present a provocative text and, at the same time, provide a behavioral reflection on the current situation of human relationships in business management, having as its core, Christian spirituality and respect for the dignity of the human person, in interpersonal relationships within workplace. We take as reference and theoretical foundation, the biblical citation of the Gospel of John chapter 4 and verses 1 to 29. There, we address the realities of net culture and the influxes of this reality, in the problematic of the human being as a relationship. It helped to deepen the theme of the theoretical contribution of Bauman (2009) and Ravasi (2014) within the paradigm of liquid thought and theological hermeneutics of the
\end{abstract}

Sóstenes Luna

Doutor em Teologia pela Universidade Gregoriana de

Roma. Colaborador da inclusão social do Centro Universitário Christus (Unichristus).

Fortaleza-CE - BR. E-mail:

$<$ p.sostenesluna@gmail.com>. 
biblical Johannine source. The aforementioned work presents in a humble and unpretentious manner the dialogue of Jesus of Nazareth and a foreign woman at the edge of a well, where the most humane method of dialoguing, welcoming and correcting a loving leader is revealed, which goes beyond the liquid reality offering a solid inner life project for that woman and for the human person who commits herself to the good of her enterprise and those who collaborate with her in a successful administrative and existential project.

Keywords: Liquid society. Paradigm of liquid thought. Theological hermeneutics.

\section{RESUMEN}

Este ensayo se trata de un texto provocativo y, al mismo tiempo, una reflexión conductual sobre la situación hodierna de las relaciones humanas en la gestión empresarial, tiendo como aporte, la espiritualidad cristiana y el respecto a la dignidad de la persona humana, en las relaciones interpersonales, dentro del ambiente de trabajo. Cogemos como referencia y fundamentación teórica, la citación bíblica del Evangelio de Juan, capítulo 4 y versículos de 1 a 29. Son abordadas las realidades de la cultura líquida y los influjos de esta realidad, en la problemática del ser humano como ente de relaciones. Nos ayudó a profundizar el tema la contribución teórica de Bauman (2009) y Ravasi (2014) dentro del paradigma del pensamiento líquido y de la hermenéutica teológica de la fuente bíblica Joanina. El presente trabajo presenta de forma humilde y presuntuosa el dialogo de Jesús y una mujer extranjera a la margen de un pozo, donde se desvela el método más humano de dialogar, acoger y corregir de un líder amoroso, que está más allá de la realidad líquida ofreciendo un sólido proyecto de vida interior para aquella mujer y para la persona humana, que se compromete con el bien de su emprendimiento y de aquellos que colaboran consigo, en un proyecto administrativo y existencial bien sucedido.

Palabras-clave: Sociedad líquida. Paradigma del pensamiento líquido. Hermenéutica teológica.

\section{INTRODUÇÃO}

Uma das páginas bíblicas mais contagiantes do ponto de vista literário e comportamental é o texto do Evangelho de João (BÍBLIA, João, 4, 1-29. A peça bíblica a que nos referimos é o famoso texto do diálogo de Jesus de Nazaré com a samaritana, à beira do Poço de Jacó.

O leitor deve estar se perguntando: porque aprofundar um texto bíblico em uma revista sobre gestão? Respondo-lhe com mansidão e humildade (BÍBLIA, Mateus, 11, 29). Fala-se muito da cultura líquida e que vivemos em um tempo, que tudo deve ser fluido e flexível. Não há espaço para o sólido e as relações humanas tornam-se, cada vez, mais superficiais e voláteis. O texto do diálogo de Jesus com a Mulher da Samaria será a fonte primária para o nosso artigo, colocando-nos diante da realidade de um Jesus gestor de emoções, com convicções consistentes sobre a inclusão da mulher no âmbito social.

'Jesus' é mestre do diálogo. Com a capacidade 'Divina' de conhecer o interior da pessoa e com a sabedoria do 'Espírito Santo' penetra no mais íntimo da alma, revelando-lhe a verdade que liberta e transforma a vida humana. Faz-se necessário ter um encontro pessoal com Jesus e beber de seus ensinamentos; por isso, nossa fonte primária, para as ideias que aqui serão defendidas são as Sagradas Escrituras.

Usaremos também o pensamento de Bauman (2009) para tentar aprofundar a problemática da "Modernidade líquida" e nos apoiaremos no texto do italiano Ravasi (2014) sobre a reflexão da fonte evangélica joanina. Nossa pretensão nesse modesto texto é provocar no leitor um desejo de "avançar para águas mais profundas" (BÍBLIA, Lucas, 5, 4) defrontando-se com o tema da "vida líquida" e acreditando em projetos dialogados e consistentes.

\section{O ENCONTRO}

Convidamos o leitor a fazer uma viagem imaginária conosco a uma das regiões mais bucólicas do globo. Vamos até a Palestina! Entre os 
montes Garizim e Ebal ${ }^{1}$ começa um estreito vale, onde hoje se situa a cidade de Naplusa ou Nablus ${ }^{2}$, a antiga Siquém ou Sicar. Essa cidade se funde com estes montes e constata-se que, na primavera, o verde, a exuberância do colorido estacional e muitas nascentes de águas fazem do local posto aprazível. Ali, ainda que, com divergências precisas sobre o local, da parte de alguns historiadores existe um poço denominado "Poço de Jacó", está localizado perto do caminho que vai de Jerusalém a Naplusa. Esse seria o local do paradigmático encontro entre Jesus de Nazaré e a Samaritana.

Narra o texto que os Fariseus ficaram sabendo que Jesus tinha mais discípulos que João Batista e que muitos seguiam seus ensinamentos (BÍBLIA, João, 1, 1-2), causando a fúria e a inveja da parte dos Fariseus. Jesus então decidiu ir de Jerusalém até a Galileia e teria que atravessar a Samaria. É interessante perceber que os Judeus não tinham uma boa relação com os samaritanos. Ao chegar a Siquém, próximo ao terreno que Jacó deu a seu filho José (BÍBLIA, Gênesis, 33, 18-20), encontra-se o "Poço de Jacó". Jesus, cansado da viagem, sentou-se à beira do poço, para refrescar-se: a narração bíblica diz que era "meio dia" (BÍBLIA, João, 4, 6). O teólogo italiano Gianfranco Ravasi em seu opúsculo 'Procurar a verdade', constata:

'Quaerens me sedisti lassus...', 'sentaste-te, cansado, para me procurares...', canta-

1 Moisés mandou que após os israelitas atravessassem o rio Jordão, deveriam ir aos montes Ebal e Garizim e que as tribos de Simeão, Levi, Judá, Issacar, José e Benjamim permanecessem nas encostas do Monte Garizim, pronunciando as bênçãos para aqueles que guardassem a lei de Deus (BÍBLIA, Deuteronômio, 11, 29; BÍBLIA, Deuteronômio, 27,12-13).

2 Naplusa ou Nablus é uma importante cidade da Cisjordânia, com 134.100 habitantes (2006), preponderantemente palestinos, embora haja cerca de 300 samaritanos. É um centro comercial e cultural palestino. Situada a aproximadamente 63 quilômetros ao norte de Jerusalém, está em uma posição estratégica, entre o Monte Ebal e o Monte Gerizim, lugares sagrados para diferentes religiões. Nablus foi a primeira capital do Reino de Israel a antiga Siquém ou Sicar (NABLUS GUIDE, 2019).

3 Poço de Jacó, também conhecido como Fonte de Jacó e Poço de Sicar, é um poço profundo escavado na rocha sólida que tem sido associado à tradição religiosa com Jacó por cerca de dois milênios. Está situado a uma curta distância do sítio arqueológico de Tell Balata, que é considerado como o local de Siquém bíblica. O poço atualmente encontra-se dentro do complexo de um mosteiro ortodoxo oriental de mesmo nome, na cidade de Naplusa, na Cisjordânia. Cf. Horne (1856, p. 50-51), Bromiley (1982, p. 955) Hastings and Driver (2004, p. 535-537). rá o célebre hino 'Dies irae"4 fazendo memória daquele momento em que, no poço de Jacob, aos pés do monte Garizim, ainda hoje sagrado para a comunidade 'heterodoxa' dos samaritanos, Jesus fez uma paragem para dialogar com aquela mulher com uma vida sentimental bastante movimentada (RAVASI, 2014, p. 36).

E confere-lhe o grande segredo da fé, possuir o 'Dom de Deus'.

Fazendo uma análise à luz da gestão, percebemos que todo administrador deve estar sereno, diante das críticas e das inúmeras dificuldades que o processo de gerir possa causar. Deve saber defrontar-se com ânimo "o dia da ira", sem deixar-se abater pelo cansaço e pela fadiga. Importante ter a certeza de que sua consciência o conduz para um bom caminho. E que, mesmo diante das inúmeras dificuldades para trabalhar com honestidade e clareza haverá sempre em meio ao caminho um 'poço' simbólico, onde possamos parar e nos refrescar.

Voltando ao contexto bíblico, a narração nos diz que chegou uma mulher da Samaria para buscar água (BÍBLIA, João, 4, 7). Aqui temos o encontro de duas pessoas: Jesus e a Mulher samaritana. O novo Adão e a Antiga Eva. Queremos instigar o leitor a uns pormenores do texto que, $a$ priori, podem passar despercebidos:

a) Jesus sai do centro (Jerusalém) e volta à Galileia, região à margem. Toma distância das problemáticas ideológicas e das pessoas contrárias a propagação do Reino de Deus e de sua missão salvífica, por meio da reação invejosa dos fariseus e dos doutores da lei;

b) Jesus caminha - $\mathrm{O}$ bom administrador deve estar sempre em busca de caminhar com o seu grupo. Deve procurar conhecer novos horizontes e buscar renovar suas energias e forças, que o árduo exercício do serviço de gerir possa provocar;

c) a certa altura da viagem, Jesus descansa à beira de um 'poço'. Esse descanso e pa-

4 'Dia de ira', famoso texto em latim, do século XIII, atribui-se tal escrito a Tomás de Celano. Sua inspiração bíblica vem do texto de Sofonias 1,15-16. Foi fonte primária para Mozart em seu famoso Requiem (acusativo de requies $=$ descanso, em português.) (DOTRO; HELDER, 2006, p. 140-141). 
rada é a antecipação de um encontro. Jesus se encontra com uma mulher e ainda mais samaritana. Rompe duas fronteiras contra a discriminação e exclusão social de sua Época: fala com uma samaritana (estrangeira) e do sexo feminino. Os judeus eram inimigos dos samaritanos e os homens não se dirigiam às mulheres nesse contexto sociocultural;

d) é muito importante perceber a hora em que Jesus se encontra com a samaritana à beira do poço: 'meio dia'. 'Meio dia' é a hora em que o sol está mais cálido e brilhante; ninguém vai buscar água no poço a essa hora. Porque essa mulher foi justamente buscar água no poço nesse horário?

Deixamos essa pergunta, para instigar o leitor a continuar adentrando nas ideias que nos fazem entender a metodologia de Jesus de Nazaré, a partir das fontes Evangélicas e da Tradição da Igreja.

\section{O DIÁLOGO}

O Capítulo 4 do Evangelho de João, precisamente no versículo 6 , diz que Jesus, cansado, sentou-se tranquilamente à beira do poço e que chegou uma mulher samaritana para tirar água.

Jesus, então, lhe disse: " - Dá-me de beber!" A mulher responde: “- Tu que és Judeu pede-me a mim, que sou samaritana?” (BÍBLIA, João, 4, 6).

Importante perceber na conversa, que Jesus toma a iniciativa e introduz o diálogo, aproxima-se da mulher por meio da palavra, ele rompe a barreira da exclusão e do machismo imperante em seu tempo e derruba o muro da separação cultural e religiosa.

O Diálogo continua; Jesus disse: “- Se conhecesses o 'dom de Deus' e quem é que te pede de beber, tu que pedirias a 'Ele' e 'Ele' te daria água viva.” (BÍBLIA, João, 4, 6).

Observemos no conteúdo do diálogo, o teor da gestão dos sentimentos utilizado por Jesus, que a priori demarca em sua conversação que necessita da mulher pedindo-lhe água. Podemos perceber que o tema a ser abordado toca a fé e as emoções, mas não fica isento de razão e da verdade existencial que a pessoa humana vive. A iniciativa do diálogo foi de Jesus, mas a mulher reage, sai de sua zona de conforto e anonimato, conversa com Jesus.

A fala de Jesus inicia-se com o conhecimento do 'Dom de Deus'. A palavra 'dom' vem do "charis" grego, que significa 'Graça'. Aprofundando ainda mais, deparamo-nos com o substantivo 'carisma' e com o adjetivo 'carismático'. Então, Jesus provocava a mulher samaritana a conhecer o verdadeiro Deus, a sua graça e o os seus dons e deixar de lado as idolatrias e os falsos deuses.

Afirma Ravasi (2014, p. 36-37): "A revelação de Cristo começa por tirar partido da água daquele poço, mas para se alargar em um discurso mais elevado e emocionante."

A samaritana continua o diálogo dizendo: “Senhor não tens com tirar água do o poço; é muito fundo, onde vais conseguir essa água viva? Por acaso, és mais poderoso que nosso Pai Jacó, que nos deu esse poço e sua água serviu a seus filhos e a seus rebanhos?" (BÍBLIA, João, 4).

Jesus lhe responde: "o que bebe desta água do poço, volta a ter sede; mas, o que bebe da água que eu darei, nunca mais terá sede, porque a água que eu darei, se converterá dentro da pessoa em um manancial que a levará à vida eterna." (BÍBLIA, João, 4).

Percebamos que, já em tempos remotos, há mais de dois milênios, Jesus toca no argumento da 'vida líquida'. Bauman (2009, p. 7) afirma que "a 'vida líquida' é uma forma de vida que tende a ser levada adiante, em uma sociedade em que as condições sob as quais agem seus membros mudam em um tempo mais curto do que aquele necessário para a consolidação, em hábitos e rotinas, das formas de agir." Em seu diálogo, Jesus contraria a 'vida líquida' afirmando que a água que Ele nos oferece, não é passageira, mas que dura até a vida eterna, fazendo-nos acreditar em experiências fortes e duradouras. Oliveira (2012) afirma que:

Em consequência da enorme individualização da sociedade líquida, o indivíduo procura na sociedade e no mercado, além de em todas suas relações sociais, a felicidade no sentido de satisfação do prazer pessoal, perdendo todo e qualquer sentido de solidariedade e compreensão do 
outro, modificando e desvirtuando a noção de moral (OLIVEIRA, 2012, p. 30).

Nesse contexto líquido em que vivemos: de que água você necessita? Não seria o momento de também experimentar da 'Água da Palavra de Deus', que sacia nossa sede pelo absoluto, que preenche os nossos vazios existenciais? A samaritana diz a Jesus: “- Senhor dá-me dessa água, para que e u não tenha que vir aqui saciar-me.” (BÍBLIA, João, 4).

Jesus provoca-a: “- Vai buscar o teu marido e volta aqui." Ela respondeu: “- Eu não tenho marido". Jesus lhe disse: “- Tens razão de dizer que não tens marido; porque, já tiveste cinco e o que tens agora não é teu marido. Nisso falaste a verdade." (BÍBLIA, João, 4).

A verdade constatada por Cristo perturba a vida e a compreensão da religião que aquela mulher praticava. O Senhor vai ao mais profundo da essência do ser. Toca de forma sólida o que está liquefeito e turvo pelas realidades de relacionamentos afetivos deturpados pela coisificação da pessoa. Cugini (2008) declara a ação em viver junto, como uma característica das novas relações afetivas da modernidade líquida, a qual, também, envolve o sentido da família; pois se a constituição familiar era, até a modernidade, um pilar fundamental da sociedade e os filhos, a consistência dessa relação, no mundo líquido pós-moderno, não é assim. Se nada tem substância, se tudo é fluido e os valores, assim chamados espirituais, nem têm mais força no novo contexto cultural, isso afeta também a estrutura familiar, comprometendo-a (CUGINI, 2008, p. 159-178).

Jesus revela a essa mulher a sua grande fragilidade afetiva, sua inconstância e liquidez. Bauman $(2009$, p. 15) diz que "graças à almejada infinidade de experiências mundanas ainda por vir, a eternidade talvez não deixe saudade, talvez nem se chegue a notar sua perda." Essa mulher teve a graça de encontrar-se pessoalmente com Jesus e deixar-se tocar por ele. Será que você também não necessita dialogar com Jesus? Só há uma forma para esse diálogo acontecer: por meio da oração. $\mathrm{O}$ gestor que reza, se errar ao menos terá o fulcro de que errou, ancorado pela busca do justo discernimento e o do desejo sólido de querer acertar (BAUMAN, 2003, p. 49-55).

\section{A CONSTATAÇÃO}

A mulher samaritana diante das revelações de Jesus chega a uma constatação: “- Senhor, vejo que és um profeta. Nossos pais adoravam nesse monte. Vocês judeus dizem que é em Jerusalém que devemos prestar culto." (BÍBLIA, João, 4).

Aqui, percebe-se claramente que o autor faz a passagem da dimensão moral para a espiritual. A samaritana constata que a sede por Deus e em sua adoração, encontra-se a fonte da fé e da experiência religiosa, de que o nosso interior necessita. Tratando da compreensão cultural, a partir da forma de vivenciar a fé: para os samaritanos, seria a adoração no Monte Garezim e para os Judeus a adoração no Templo de Jerusalém. Foi necessário Jesus revelar o mais profundo do drama existencial daquela mulher, provocando-a a deixar seus falsos deuses e reconhecer em Jesus o Messias. De forma explícita, a mulher tinha uma vida sentimental tumultuada, que nos conduz à interpretação e à associação de seus tantos maridos, aos pseudo-deuses que os samaritanos adoravam.

Continuando a narração evangélica, Jesus diz:

- Crê, mulher, - chegará a hora que nem neste monte e nem em Jerusalém se dará culto ao Pai. Vocês cultuam o que não conhecem, nós damos culto ao que conhecemos, porque a salvação procede dos Judeus. Porém, chegará a hora, e já chegou, a que os que dão culto autêntico adorarão ao Pai em Espírito e verdade, porque esses são os adoradores que buscam o Pai. Deus é Espírito e os que o adoram devem fazê-lo em espírito e verdade (BÍBLIA, João, 4).

Jesus toca na problemática do conhecimento de Deus e provoca a samaritana a fazer uma experiência espiritual com Deus, a partir do encontro com Ele na beira do poço. Revela-lhe o autêntico culto e a motiva a deixar aquela vida de idolatria optando por viver para Deus. Nos tempos atuais, a pessoa humana vive "a 'síndrome consumista' a que a cultura contemporânea se rende cada vez mais, e que tem como centro, uma enfática negação do preceito de "retardar a satisfação"" (BAUMAN, 2009, p. 83). 
Aquela mulher bíblica buscou em seus tantos maridos uma satisfação imediata de viver seus sentimentos, deixando-se conduzir por uma falsa experiência de amor. Jesus, porém, mostrou-lhe que, em Deus e na sólida experiência do amor desinteressado, encontra-se a verdadeira via para a felicidade e para uma refutação da cultura do consumo e do descarte dos nossos tempos.

\section{CONCLUSÃO}

O texto da hodierna página evangélica revela-nos a identidade de Jesus. Ele é o messias, ou seja, o Cristo, e que a mulher, ao se deparar com essa constatação, larga fora o seu cântaro e sai anunciando a todos que se encontrou com alguém, que disse tudo o que ela tinha feito (BÍBLIA, João, 4, 26-29).

O encontro pessoal com Jesus transforma a vida e a história de quem se deixar tocar por Ele. Imaginemos a atmosfera de uma empresa que consegue exorcizar a inveja entre os seus colaboradores, a fofoca, a luxúria, a preguiça, os ciúmes, a competição desmedida, a falta de interesse e de coletividade ${ }^{5}$ ? Certamente, com esses atributos, as relações humanas seriam bem mais sólidas e consistentes.

A rocha que é Cristo e o fundamento de seu ensinamento, fazem-nos perceber que suas palavras não passam e que, por mais confusos que sejam os tempos, haverá sempre espaço para o amor. Encontrar-se com Jesus no campo da gestão, é optar por um mecanismo de busca da verdade e da ética que pressupõe qualquer ação que prejudique ao próximo.

Reconhecer que Jesus pode dar-nos o que necessitamos, será o antídoto para combater qualquer tipo de gestão que oprima ou descarte o ser humano. O líder humilde é aquele capaz de agregar junto de si os valores mais altos da dignidade do ser humano. Quais são os cântaros que devemos deixar, para ousarmos em uma gestão inovadora e sempre mais voltada para o Evangelho?

\section{REFERÊNCIAS}

BAUMAN, Zygmunt. Comunidade: a busca por segurança no mundo atual. Rio de Janeiro Zahar, 2003.

BAUMAN, Zygmunt. Vida Líquida. Rio de Janeiro: Zahar, 2009.

BÍBLIA, Português. Bíblia de Jerusalém. São Paulo: Paulus, 2002.

CUGINI, P. Identidade, afetividade e a mudanças relacionais na modernidade líquida na teoria de Zygmunt Bauman. Revista Diálogos Possíveis, Bahia, v. 17, n. 2, p. 159-178, jan./jun. 2008. Disponível em: http://revistas.faculdadesocial.edu.br/ index.php/dialogospossiveis. Acesso em: 4. abr. 2019.

DOTRO, Ricardo Pascual; HELDER, Geraldo Garcia. Dicionário de Liturgia. São Paulo: Loyola, 2006.

FRANCISCO, Papa. Exortação Apostólica: Gaudete et Exsultate. Roma: Libreria Vaticana, 2018.

NABLUS GUIDE. Welcome to Nablus Guide. Disponível em: http://www.nablusguide.com/. Acesso em: 4. abr. 2019.

OLIVEIRA, L. P. Zygmunt Bauman: a sociedade contemporânea e a sociologia na modernidade líquida. Revista Sem Aspas, Araraquara, São Paulo, v. 1, n. 1, p. 25-36, jan./jun. 2012. Disponível em: https://periodicos. fclar.unesp.br/semaspas/ article/view/6970. Acesso em: 4. abr. 2019.

RAVASI, Gianfranco. Procurar a verdade. Lisboa: Paulus, 2014.

5 Cf. Francisco (2018, p. 97). Aqui Francisco consegue individuar todas as inclinações que desviam o ser humano da harmonia e integração com os outros. 